\title{
Clinical implications of proliferation activity in T1 or T2 male gastric cancer patients
}

\author{
Young-Woo Kim ${ }^{1,2}$, Bang Wool Eom ${ }^{1,2}$, Myeong-Cherl Kook ${ }^{1,2}$, Han-Seong Kim ${ }^{3}$, Mi-Kyung Kim ${ }^{1}$, \\ Hai-Li Hwang ${ }^{1}$, Vishal Chandra ${ }^{1}$, Shiv Poojan ${ }^{1}$, Yura Song ${ }^{1}$, Jae-Soo Koh ${ }^{4}$, Chang-Dae Bae ${ }^{5}$, Jungsil Ro ${ }^{1,2}$ \\ and Kyeong-Man Hong ${ }^{1}$
}

Proliferation activity has already been established as a prognostic marker or as a marker for anticancer drug sensitivity. In gastric cancer, however, the prognostic significance of proliferation activity is still being debated. Several studies evaluating proliferation activity using Ki-67 have shown controversial results in terms of the relationship between proliferation activity and overall survival (OS) or drug sensitivity in gastric cancer patients. Because cytoskeleton-associated protein 2 (CKAP2) staining has recently been introduced as a marker of proliferation activity, we analyzed 437 gastric cancer tissues through CKAP2 immunohistochemistry, and we evaluated the chromatin CKAP2-positive cell count (CPCC) for proliferation activity. Although the CPCC did not show any significant correlation with OS in the male, female or total number of cases, it did show a significant correlation in the T1 or T2 male patient subgroup, according to log-rank tests $(P=0.001)$ and univariate analysis $(P=0.045)$. Additionally, multivariate analysis with the Cox proportional hazard regression model showed a significant correlation between the CPCC and OS $(P=0.039)$ for the co-variables of age, gender, $\mathrm{T}$ stage, $\mathrm{N}$ stage, histology, tumor location, tumor size and adjuvant chemotherapy. In male gastric cancer cell lines, faster-growing cancer cells showed higher sensitivity to cisplatin than slow-growing cells. Thus our study indicates that CPCC-measured proliferation activity demonstrates a significantly worse prognosis in T1 or T2 male gastric cancer patients. The CPCC will help to more precisely classify gastric cancer patients and to select excellent candidates for adjuvant chemotherapy, which in turn will facilitate further clinical chemotherapeutic trials. Experimental \& Molecular Medicine (2015) 47, e193; doi:10.1038/emm.2015.79; published online 6 November 2015

\section{INTRODUCTION}

Because cell proliferation is one of the most vital biological mechanisms in oncogenesis, ${ }^{1}$ cell proliferation activity has been posited as a promising prognostic marker. Whereas the prognostic significance of cell proliferation activity has been well established in various cancers, including breast cancers, meningiomas, gastrointestinal stromal tumors and head and neck cancers, ${ }^{2-5}$ its utility remains in doubt in other cancers. Particularly in cases of gastric cancer, while some studies have reported a positive correlation between higher proliferation and worse survival, ${ }^{6}$ others have demonstrated no such relationship. ${ }^{7-9}$ Recently, an inverse correlation was reported in a relatively large ( 245 cases) cohort. ${ }^{10}$ Therefore, additional studies are required to clarify the prognostic significance of proliferation activity in gastric cancer.

High proliferation activity has been related to greater sensitivity to anticancer drugs. ${ }^{11}$ In breast cancer, for example, proliferation has been recognized as a reliable predictor of the response to adjuvant ${ }^{12,13}$ and neoadjuvant chemotherapy. ${ }^{14-16}$ In gastric cancer, however, the correlation between proliferation activity and anticancer drug sensitivity remains unclear. If such a correlation is also observed in gastric cancer, the measurement of proliferation activity for that disease could have therapeutic implications.

Ki-67 and mitotic counts have been the most widely employed tools used to evaluate proliferation activity in various cancers, including gastric cancer. Cytoskeleton-associated protein 2 (CKAP2) has been recently established as a new mitotic marker, with chromatin CKAP2-positive cells being identified as mitotic cells ${ }^{17}$; indeed, there is a strong correlation between the CKAP2-positive cell count (CPCC) and the mitotic figure count. ${ }^{18}$ The prognostic significance of the CPCC has also been demonstrated in breast cancer, for which it was equivalent to or better than the significance of the mitotic activity index, ${ }^{19}$ one of the most widely accepted proliferation activity measurements in breast cancer. ${ }^{20}$ In the

${ }^{1}$ Research Institute, National Cancer Center, Goyang, Korea; ${ }^{2}$ National Cancer Center Hospital, National Cancer Center, Goyang, Korea; ${ }^{3}$ Department of Pathology, Inje University Ilsan Paik Hospital, Goyang, Korea; ${ }^{4}$ Department of Pathology, Korea Cancer Center Hospital, Seoul, Korea and ${ }^{5}$ Department of Molecular Cell Biology, Sungkyunkwan University School of Medicine, and Samsung Biomedical Research Institute, Suwon, Korea

Correspondence: Dr K-M Hong, Research Institute, National Cancer Center, 323 IIsan-ro, Ilsandong-gu, Goyang 410-769, Korea.

E-mail: kmhong@ncc.re.kr

Received 6 May 2015; revised 30 June 2015; accepted 21 July 2015 
present study, to evaluate the prognostic significance of proliferation activity in gastric cancer, CKAP2 immunohistochemical staining was performed on 437 gastric cancer tissues, and the correlation between the CPCC and overall survival (OS) was evaluated.

\section{MATERIALS AND METHODS}

Patients, specimens and cell lines

Cases of gastric cancer patients who underwent curative resection at the National Cancer Center between 2002 and 2003 were accrued, and microarrays were created from paraffin-embedded tissues from 521 gastric cancer patients. Access to and usage of the patients' clinical information and the relevant archival tissues were approved by the Institutional Review Board of the National Cancer Center, which waived the need for informed consent. The human male gastric cancer cell lines Kato III, SNU-484, SNU-601 and SNU-668 were obtained from the Korean Cell Line Bank (http://cellbank.snu.ac.kr) and cultured in RPMI-1640 culture media (Thermo Fisher Scientific Hyclone, Logan, UT, USA) containing $10 \%$ fetal bovine serum (Thermo Fisher Scientific Hyclone) at $37^{\circ} \mathrm{C}$ under $5 \% \mathrm{CO}_{2}$.

\section{Immunohistochemistry}

Immunohistochemical staining was performed using the Ultravision LP Detection kit (Thermo Fisher Scientific Inc., Fremont, CA, USA), as previously reported, for the same CKAP2 antibody. ${ }^{12}$ Briefly, after deparaffinization of the formalin-fixed, paraffin-embedded tissues, antigen was retrieved in $10 \mathrm{~mm}$ citrate buffer, $\mathrm{pH} 6.0$, containing $0.05 \%$ Tween 20 . The tissues were sequentially treated with $3 \%$ hydrogen peroxide and Ultra V block solution for 15 min each. After being incubated for $1 \mathrm{~h}$ at room temperature with anti-CKAP2 antibody, the slides were washed in Tris-buffered saline with Tween
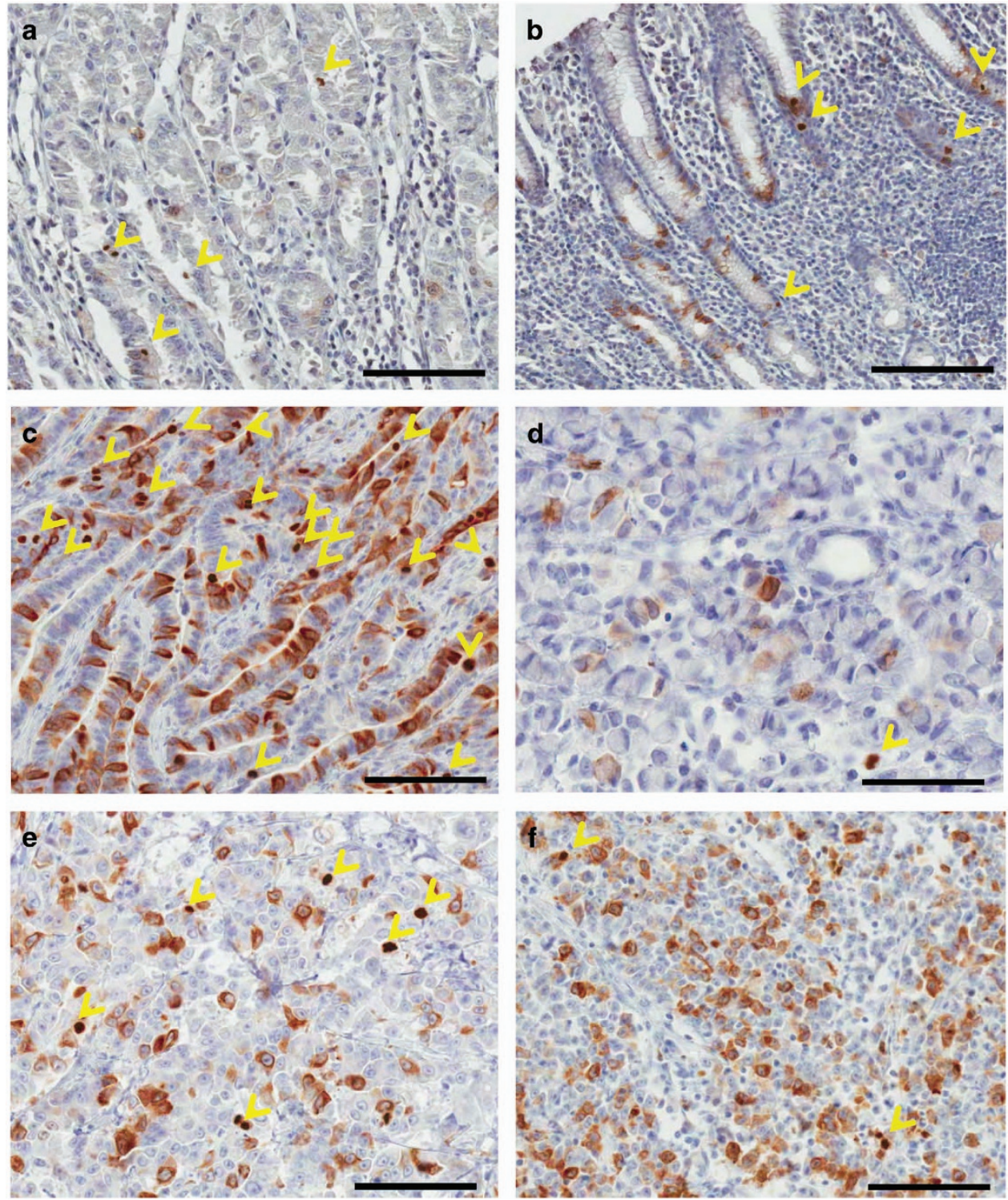

Figure 1 CKAP2 immunohistochemical staining pattern in gastric cancer tissues. (a) Normal stomach body adjacent to cancer cells. (b) Normal stomach antrum adjacent to cancer cells. (c) Intestinal type and well-differentiated adenocarcinoma. (d) Signet-ring cell carcinoma. (e) Poorly differentiated adenocarcinoma. (f) Poorly differentiated adenocarcinoma with a relatively high number of cytoplasmic CKAP2-positive cells. The yellow arrow heads indicate chromatin CKAP2-positive cells. Each bar represents $100 \mu \mathrm{m}$. 
20 (TBST), incubated with primary antibody enhancer for $10 \mathrm{~min}$ and exposed to horseradish peroxidase-conjugated secondary antibody for $15 \mathrm{~min}$. After re-washing in TBST, the tissue slides were incubated with diaminobenzidine chromogen (Scytek Laboratories Inc., Logan, UT, USA) and counterstained with Mayer's hematoxylin (Dako Cytomation, Glostrup, Denmark).

Table 1 Correlation between the CPCC and clinicopathological characteristics of the study population

\begin{tabular}{|c|c|c|c|c|}
\hline Variable & Group & $\mathrm{N}$ & $\begin{array}{c}\text { Median CPCC } \\
\text { (quartile range) }\end{array}$ & $\mathrm{P}$ \\
\hline \multirow[t]{2}{*}{ Gender } & Male & 301 & $12(6,21)$ & \\
\hline & Female & 136 & $8(2,17)$ & 0.002 \\
\hline \multirow[t]{4}{*}{ Age, years } & $<50$ & 119 & $8(2,17)$ & \\
\hline & $50-59$ & 123 & $13(5.5,20)$ & 0.003 \\
\hline & $60-69$ & 146 & $11(5,20.8)$ & 0.009 \\
\hline & $\geqslant 70$ & 49 & $11(5,23)$ & 0.011 \\
\hline \multirow{4}{*}{$\begin{array}{l}\text { Histologic } \\
\text { type (WHO) }\end{array}$} & WD or MD & 166 & $13(6,21.8)$ & \\
\hline & PD & 178 & $10(4,18.8)$ & 0.071 \\
\hline & SRC & 68 & $5.5(2,12)$ & $<0.001$ \\
\hline & Others & 25 & $18(6.75,44.75)$ & 0.068 \\
\hline \multirow{4}{*}{$\begin{array}{l}\text { Lauren } \\
\text { classification }\end{array}$} & Intestinal & 207 & $12(6,21)$ & \\
\hline & Diffuse & 151 & $6(2,14.8)$ & $<0.001$ \\
\hline & Mixed & 36 & $10(5,19.8)$ & 0.343 \\
\hline & Unknown & 43 & $14.5(9.3,32.5)$ & 0.010 \\
\hline \multirow{4}{*}{$\begin{array}{l}\text { Depth of } \\
\text { invasion }\end{array}$} & $\mathrm{T} 1$ & 183 & $9(3.5,17)$ & \\
\hline & T2 & 44 & $15(4,28)$ & 0.035 \\
\hline & T3 & 83 & $11(5,18)$ & 0.200 \\
\hline & T4 & 127 & $12(6,22)$ & 0.038 \\
\hline \multirow{4}{*}{$\begin{array}{l}\text { LN } \\
\text { metastasis }\end{array}$} & NO & 219 & $10(4,18.5)$ & \\
\hline & N1 & 50 & $12.5(6,22)$ & 0.351 \\
\hline & $\mathrm{N} 2$ & 58 & $11(5,17)$ & 0.586 \\
\hline & N3 & 110 & $11(5,23.5)$ & 0.340 \\
\hline \multirow[t]{2}{*}{ Metastasis } & No & 411 & $11(4,20)$ & \\
\hline & Yes & 26 & $8.5(6,14.5)$ & 0.840 \\
\hline \multirow[t]{4}{*}{ Tumor location } & Middle & 81 & $8(4,17)$ & \\
\hline & Upper & 53 & $9(2,16)$ & 0.624 \\
\hline & Lower & 263 & $11(5,21)$ & 0.050 \\
\hline & Overlapping & 40 & $13(4.8,22)$ & 0.153 \\
\hline \multirow[t]{4}{*}{ Tumor size } & $1(\leqslant 3.0 \mathrm{~cm})$ & 99 & $10(3,18)$ & \\
\hline & $2(>3.0, \leqslant 5.0 \mathrm{~cm})$ & 144 & $10(5,8)$ & 0.473 \\
\hline & $3(>5.0, \leqslant 7.0 \mathrm{~cm})$ & 90 & $13(5,21)$ & 0.142 \\
\hline & $4(>7.0 \mathrm{~cm})$ & 109 & $11(5,24)$ & 0.109 \\
\hline \multirow{2}{*}{$\begin{array}{l}\text { Adjuvant } \\
\text { chemotherapy }\end{array}$} & No & 207 & $10(4,18)$ & \\
\hline & Yes & 230 & $11.5(5,22)$ & 0.065 \\
\hline
\end{tabular}

Abbreviations: CPCC, chromatin CKAP2 (cytoskeleton-associated protein 2)positive cell count; LN, lymph node; MD, moderately differentiated adenocarcinoma; PD, poorly differentiated adenocarcinoma; SRC, signet-ring cell carcinoma; WD, well-differentiated adenocarcinoma; WHO, World Health Organization. Significant values are shown in bold.

\section{Chromatin CPCC counts}

In the CPCC determination, the number of chromosomal CKAP2positive cells under one $\times 200$ power field (instead of $10 \times 400$ power fields) was counted because of the limited number of microscopic fields in the tissue microarrays. Strongly to moderately stained chromatin-positive cells were included in the count. Cores containing $<50 \%$ tumor area were excluded, and finally, 437 of the original 521 cases were statistically analyzed.

\section{Cell doubling time (DT) assay}

Kato III, SNU-484, SNU 601 and SNU-668 cells $\left(1.5 \times 10^{3}\right.$ cells per well) were seeded in 24 -well plates for 24 or $48 \mathrm{~h}$ of incubation, in sixwell plates for 72 or $96 \mathrm{~h}$ of incubation or in 25 -mm flasks for 120 or $144 \mathrm{~h}$ of incubation. The cell number was counted after trypsinization into a single cell suspension. The cell DT was calculated using the software tool introduced by Roth (http://www.doubling-time.com/ compute.php) according to the following formula: $\mathrm{DT}=\left(t-t_{0}\right)$ $\log 2 /\left(\log N-\log N_{0}\right)$, where $t$ and $t_{0}$ are the time points at counting and initial plating, respectively, and $N$ and $N_{0}$, respectively, are the cell numbers at those same time points. Experiments were performed in triplicate, and the results were recorded as the mean DT \pm s.d.

\section{Cell growth after cisplatin treatment}

Cells (Kato III, SN-484, SNU 601, SNU-668) were plated at 3-7 $\times 10^{4}$ cells per well in 24-well plates. After $24 \mathrm{~h}$ of incubation, the cells were incubated for a further $72 \mathrm{~h}$ with cisplatin, an anticancer agent, at various concentrations $(0,1,2.5,5,10$ and $20 \mu \mathrm{M})$. Subsequently, the cells were fixed with $4 \%$ formaldehyde at room temperature for $5 \mathrm{~min}$ and then stained with crystal violet (Sigma, St Louis, MO, USA) for $10 \mathrm{~min}$. Upon completion of the washing and drying procedures, the cells were solubilized with $1 \%$ sodium dodecyl sulfate, and the absorbance at $595 \mathrm{~nm}$ was measured. The data were normalized to the untreated controls. Experiments were performed in three independent assays, each in triplicate. The dose-response curve was plotted using a non-linear regression model, and the $\mathrm{IC}_{50}$ was determined from the fitted curves using GraphPad Prism, version 5 (GraphPad Software Inc., San Diego, CA, USA).

\section{Statistical analysis}

The correlation between the CPCC and the clinicopathological parameters was analyzed with a two-sided Wilcoxon rank-sum test, and a $P$-value $<0.05$ was considered to be statistically significant. To estimate the prognostic significance of the CPCC, total cases were equally divided into three groups based on the CPCC: group 1, $\leqslant 6(N=156)$; group $2,7-17(N=151)$; and group $3, \geqslant 18(N=130)$. OS was defined as the time from radical surgical resection to either the most recent follow-up date or until death. In Kaplan-Meier plots of the correlation with OS, the prognostic significance was analyzed using a log-rank test. Multivariate analyses were performed using Cox's proportional hazard regression model (hazard ratios with 95\% confidence intervals (CIs)) after adjusting for age, gender, $\mathrm{T}$ stage, $\mathrm{N}$ stage, metastasis, histology, tumor location, tumor size and adjuvant chemotherapy. The linear trend was calculated using the median value for each exposure parameter as a continuous variable. The correlation between the DT and the sensitivity to cisplatin was tested with Spearman's correlation test. The statistical analyses were performed with GraphPad Prism or STATA version 13 (StataCorp LP, College Station, TX, USA). 

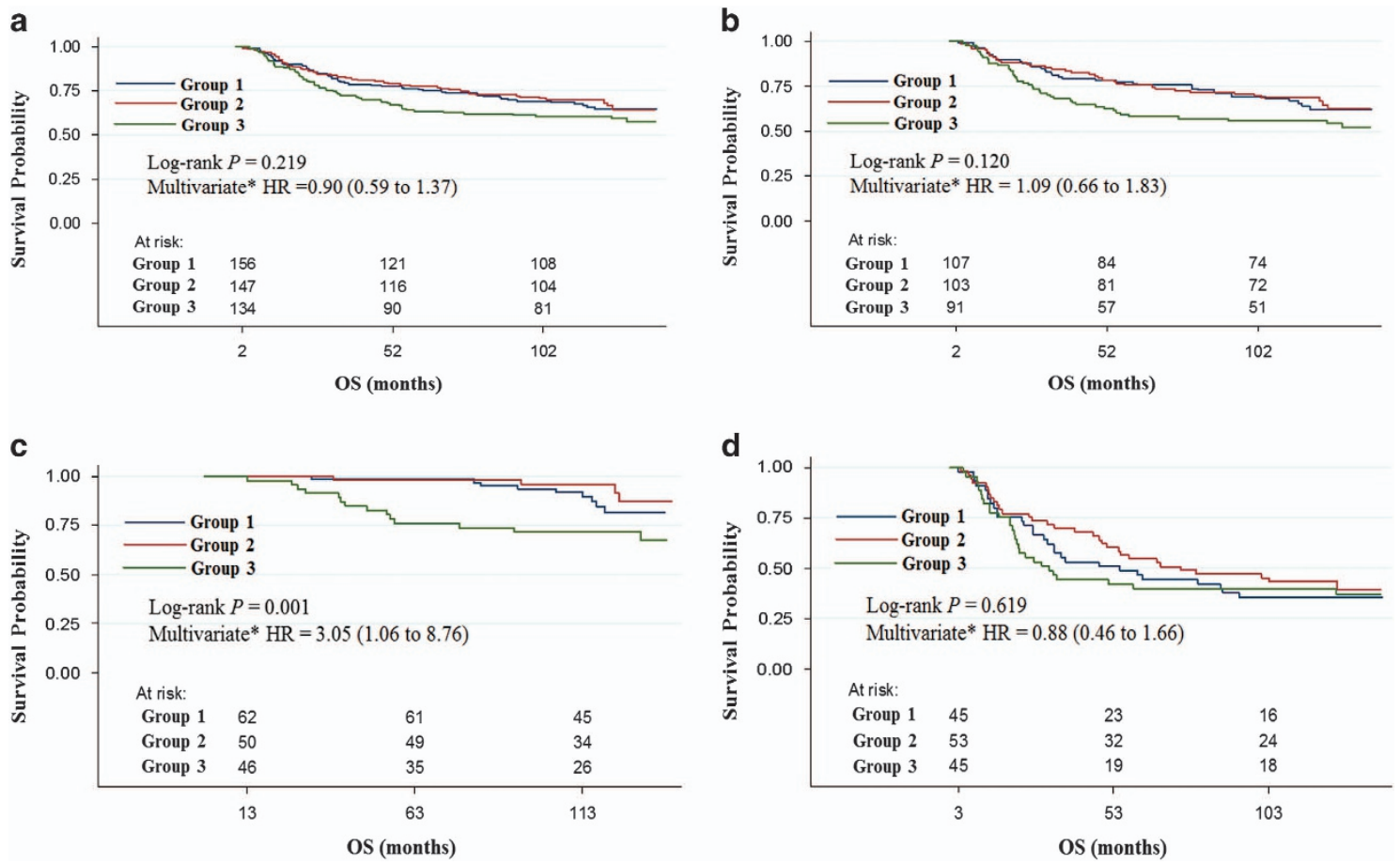

Figure 2 Correlation between the CPCC and OS. Kaplan-Meier plots of the CPCCs for the (a) total, (b) male, (c) T1 or T2 male and (d) T3 or T4 male gastric cancer cases are shown. The P-values were determined through a log-rank test. The HRs and 95\% Cls of the CPCC group 3 (highest tertile, CPCC $\geqslant 18$ ) are compared with the CPCC group 1 (lowest tertile, CPCC $\leqslant 6$ ) through multivariate analyses, as shown. The numbers at risk are also shown. CPCC, chromatin CKAP2-positive cell count; $x$ axis, OS in months; $y$ axis, survival probability.

\section{RESULTS}

Immunostaining patterns of CKAP2 in gastric cancer tissues Immunohistochemical staining of normal gastric tissues adjacent to cancer cells revealed few chromatin CKAP2positive cells and a low CPCC (Figures 1a and b). In the gastric cancer tissues, the CPCC varied according to the pathological type: the level by World Health Organizaation classification was relatively higher in well-differentiated adenocarcinomas (Figure 1c) than in signet-ring cell carcinomas (Figure 1d). The level by Lauren classification was relatively higher in the intestinal type (Figure 1a) than in the diffuse type (Figures 1e and f). In several cases of low CPCC, many cytoplasmic CKAP2-positive cells that might have been in the G2 phase and had not progressed to the mitotic phase (possibly G2-arrested cells) were shown (Figure 1f), but their significance was not evaluated in the present study.

\section{Correlation between the CPCC and clinicopathological characteristics}

The clinicopathological characteristics of the 437 gastric cancer patients are provided in Table 1. The CPCC distribution was 0-170, with a median value of 11 (quartile range, 4-20). Wilcoxon rank-sum tests showed that the median was higher for males than for females $(P=0.002$, Table 1$)$ and also higher for the older age groups than for the younger age groups ( $<50$ years $)(P=0.003-0.011$, Table 1$)$. The CPCC distribution was also significantly higher in cases with a higher $\mathrm{T}$ classification or depth of invasion (Table 1). All CPCCs differed markedly by pathological type: the level was significantly lower in signet-ring cell carcinoma than in well-differentiated or moderately differentiated adenocarcinoma $(P<0.001)$, and it was lower in the diffuse type than in the intestinal type $(P<0.001$, Table 1$)$. However, the CPCC did not differ significantly by the presence of metastasis, lymph node metastasis or tumor size (Table 1).

\section{No significant correlation between the CPCC and OS in overall gastric cancer cases}

The patients were allocated into three subgroups based on their CPCC values (group 1, 0-6; group 2, 7-17; group 3, $\geqslant 18$ ). No significant correlation with OS was found for the total number of gastric cancer cases, according to the log-rank test $(P=0.219$, Figure 2a), univariate analysis $(P=0.188$, Table 2$)$ or multivariate analysis using the co-variables of age, gender, $\mathrm{T}$ classification, $\mathrm{N}$ classification, metastasis, histological type, tumor location, tumor size and adjuvant chemotherapy $(P=0.612$, Table 2$)$.

\section{Correlation between the CPCC and OS in gastric cancer subgroups}

To investigate the prognostic significance of the CPCC in subgroups of gastric cancer, the possible subgroups were deduced based on the differential CPCC levels among the clinical parameters. Because there was a significant difference in the CPCC between male and female patients $(P=0.002$, Table 1), they were analyzed separately. However, in a log-rank test, the CPCC showed no significant correlation with OS in either the male $(P=0.120$, Figure $2 \mathrm{~b})$ or female patients 
Table 2 Univariate and multivariate analyses of overall survival for each clinicopathological parameter and CPCC

\begin{tabular}{|c|c|c|c|}
\hline \multirow[b]{2}{*}{ Variable } & \multirow[b]{2}{*}{ Group } & \multicolumn{2}{|c|}{ Total } \\
\hline & & $H R(95 \% \mathrm{Cl})$ & $\mathrm{P}^{\mathrm{a}}$ \\
\hline Gender & Female & $0.75(0.52-1.08)$ & 0.119 \\
\hline \multirow[t]{3}{*}{ Age, years } & $<50$ & 1 & $(<0.001)$ \\
\hline & $50-59$ & $0.92(0.56-1.50)$ & 0.726 \\
\hline & $\geqslant 70$ & $2.59(1.57-4.28)$ & $<0.001$ \\
\hline \multirow[t]{4}{*}{ Histology (WHO) } & WD-MD & 1 & \\
\hline & PD & 1.89 (1.32-2.72) & 0.001 \\
\hline & $\mathrm{SRC}$ & $0.91(0.52-1.59)$ & 0.748 \\
\hline & Others & $2.34(1.26-4.33)$ & 0.007 \\
\hline Lauren classification & Intestinal & 1 & \\
\hline \multirow[t]{4}{*}{ Depth of invasion } & $\mathrm{T} 1$ & 1 & $(<0.001)$ \\
\hline & $\mathrm{T} 2$ & $2.43(1.13-5.24)$ & 0.023 \\
\hline & T3 & $5.60(3.47-10.36)$ & $<0.001$ \\
\hline & $\mathrm{T} 4$ & 11.75 (7.13-19.35) & $<0.001$ \\
\hline \multirow[t]{4}{*}{ LN metastasis } & NO & 1 & $(<0.001)$ \\
\hline & N1 & $2.79(1.54-5.04)$ & 0.001 \\
\hline & N2 & $4.43(2.65-7.43)$ & $<0.001$ \\
\hline & N3 & $9.29(6.11-14.12)$ & $<0.001$ \\
\hline \multirow[t]{2}{*}{ Metastasis } & No & 1 & \\
\hline & Yes & $7.94(5.06-12.45)$ & $<0.001$ \\
\hline Tumor location ${ }^{b}$ & Upper & 1 & \\
\hline \multirow[t]{2}{*}{ Adjuvant chemotherapy } & No & 1 & \\
\hline & Yes & $5.45(3.65-8.13)$ & $<0.001$ \\
\hline \multirow[t]{3}{*}{ CPCC (univariate) } & Group $1(\leqslant 6, N=156)$ & 1 & $(0.188)$ \\
\hline & Group $2(7-17, N=151)$ & $0.94(0.64-1.40)$ & 0.765 \\
\hline & Group $3(\geqslant 18, N=130)$ & 1.30 (0.89-1.89) & 0.178 \\
\hline \multirow[t]{3}{*}{ CPCC (multivariate) ${ }^{\mathrm{C}}$} & Group $1(\leqslant 6, N=156)$ & 1 & $(0.620)$ \\
\hline & Group $2(7-17, N=151)$ & $0.80(0.52-1.23)$ & 0.301 \\
\hline & Group $3(\geqslant 18, N=130)$ & $0.90(0.59-1.37)$ & 0.610 \\
\hline
\end{tabular}

Abbreviations: $\mathrm{Cl}$, confidence interval; CPCC, chromatin CKAP2 (cytoskeleton-associated protein 2)-positive cell count; HR, hazard regression; LN, lymph node; MD, moderately differentiated adenocarcinoma; PD, poorly differentiated adenocarcinoma; SRC, signet-ring cell carcinoma; WD, well-differentiated adenocarcinoma; WHO, World Health Organization.

aThe $P$-value from the univariate or multivariate analyses is shown. The $P$-value for the linear trend is shown in parentheses.

bThe tumor location was classified as follows: upper tumor, tumor located in the upper $1 / 3$ of the stomach; middle tumor, tumor located in the middle $1 / 3$ of the stomach;

lower tumor, tumor located in the lower $1 / 3$ of the stomach; overlapping tumor, tumor at the borderline between upper and middle tumors or between middle and lower tumors. cMultivariate analysis with a Cox proportional hazard regression model was used with the co-variables of age, T stage, $\mathrm{N}$ stage, histology, tumor location, tumor size, and adjuvant chemotherapy. All patients included in the univariate analysis were also included in the multivariate analysis.

Significant values are shown in bold.

$(P=0.697$, Supplementary Figure S1). Correspondingly, the univariate and multivariate analyses showed no significance (Table 3). However, worse OS among CPCC group 3 was more marked among the male patients than among the total cohort.
Additionally, because the CPCCs were significantly higher in the advanced $\mathrm{T}$ classification cases, $\mathrm{T}$ subgroups were formed. Male patients, given the marginality of the prognostic significance among them, were analyzed separately in terms of the 
Table 3 Univariate and multivariate analyses of overall survival in various gastric cancer patient subgroups, according to CPCC

\begin{tabular}{|c|c|c|c|c|c|c|}
\hline \multirow[b]{2}{*}{ Subgroup } & \multirow[b]{2}{*}{ Group } & \multirow[b]{2}{*}{$\mathrm{N}$} & \multicolumn{2}{|c|}{ Univariate } & \multicolumn{2}{|c|}{ Multivariate } \\
\hline & & & $H R(95 \% \mathrm{Cl})$ & $P$ & $H R(95 \% \mathrm{Cl})$ & $P$ \\
\hline \multirow[t]{3}{*}{ Male } & Group $1(\leqslant 6)$ & 107 & 1 & & 1 & \\
\hline & Group 2 (7-17) & 103 & $0.95(0.60-1.51)$ & 0.835 & $0.71(0.42-1.21)$ & 0.206 \\
\hline & Group $3(\geqslant 18)$ & 91 & $1.45(0.93-2.25)$ & 0.097 & $1.09(0.66-1.83)$ & 0.715 \\
\hline \multirow[t]{3}{*}{ T1 or T2 male } & Group $1(\leqslant 6)$ & 62 & 1 & & 1 & \\
\hline & Group 2 (7-17) & 50 & $0.55(0.17-1.77)$ & 0.315 & $1.42(0.38-5.33)$ & 0.602 \\
\hline & Group $3(\geqslant 18)$ & 46 & $2.36(1.02-5.46)$ & 0.045 & 3.05 (1.06-8.76) & 0.039 \\
\hline \multirow[t]{3}{*}{ T3 or T4 male } & Group $1(\leqslant 6)$ & 45 & 1 & & 1 & \\
\hline & Group 2 (7-17) & 53 & $0.83(0.50-1.37)$ & 0.461 & $0.75(0.40-1.43)$ & 0.386 \\
\hline & Group $3(\geqslant 18)$ & 45 & $1.05(0.62-1.77)$ & 0.854 & $0.88(0.46-1.66)$ & 0.684 \\
\hline \multirow[t]{3}{*}{ Female } & Group $1(\leqslant 4)$ & 50 & 1 & & 1 & \\
\hline & Group 2 (5-13) & 42 & $1.03(0.50-2.14)$ & 0.935 & $1.68(0.59-4.81)$ & 0.333 \\
\hline & Group $3(\geqslant 14)$ & 44 & $0.75(0.35-1.62)$ & 0.467 & $0.88(0.36-2.14)$ & 0.773 \\
\hline
\end{tabular}

Abbreviations: $\mathrm{Cl}$, confidence interval; CPCC, chromatin CKAP2 (cytoskeleton-associated protein 2)-positive cell count; HR, hazard regression.

aMultivariate analysis with a Cox proportional hazard regression model was used with the co-variables of age, T stage, N stage, histology, tumor location, tumor size, and adjuvant chemotherapy. All patients included in the univariate analysis were also included in the multivariate analysis.

Significant values are shown in bold.

$\mathrm{T}$ classification. We found a significant correlation between CPCC and OS in T1 or T2 male patients $(P=0.001$, Figure $2 \mathrm{c})$ but not in T3 or T4 male patients $(P=0.619$, Figure $2 \mathrm{~d})$. The correlation was also significant according to the univariate analysis $(P=0.045$, Table 3$)$ and multivariate analysis using the co-variables of age, gender, $\mathrm{T}$ classification, $\mathrm{N}$ classification, histological type, tumor location, tumor size and adjuvant chemotherapy $(P=0.039$, Table 3$)$. In the relapse-free survival analysis, CPCC also demonstrated a significant correlation in T1 or T2 male patients $(P=0.010, \log$-rank test).

\section{Correlation of cell DT with $\mathrm{IC}_{50}$ for cisplatin}

In the assessment of DT for the four male gastric cancer cell lines, the results varied: Kato III, $30 \mathrm{~h}$; SNU-484, 28 h; SNU-668, $25 \mathrm{~h}$; and SNU-601, $18 \mathrm{~h}$ (Figure 3a). In the evaluation of $\mathrm{IC}_{50}$ for cisplatin, the results for Kato III, SNU-484, SNU-668 and SNU 601 were 8, 7, 5 and $1.5 \mu \mathrm{M}$, respectively (Figure $3 \mathrm{~b}$ ). Although not statistically significant, a positive correlation between $\mathrm{DT}$ and $\mathrm{IC}_{50}$ was observed ( $R=0.999, \quad P=0.083$ by Spearman's correlation test, Figure $3 \mathrm{c}$ ), suggesting a relationship between faster growth rate and greater sensitivity to cisplatin.

\section{DISCUSSION}

To clarify the prognostic significance of proliferation activity in gastric cancer, the CPCC was determined in 437 gastric cancer cases using CKAP2 immunohistochemical staining. Although the prognostic value of the CPCC among the total gastric cancer patients was not significant $(P=0.219)$, it was significant in the $\mathrm{T} 1$ or $\mathrm{T} 2$ male patient subgroup $(P=0.001)$. Multivariate analysis revealed that the CPCC showed prognostic significance $(P=0.039)$ for the co-variables of age, gender, $\mathrm{T}$ classification, $\mathrm{N}$ classification, histological type, tumor location, tumor size and adjuvant chemotherapy.
Our results suggest that proliferation activity is a significant prognostic factor in T1 or T2 male gastric cancer patients.

The prognostic significance of proliferation activity in gastric cancer has been controversial. Most relevant studies have found no such prognostic significance in gastric cancer, ${ }^{7-9}$ whereas one investigation reported a positive correlation between proliferation activity and worse OS. ${ }^{6}$ In contrast to both of these results (negative and positive), we observed a positive correlation only in the $\mathrm{T} 1$ or $\mathrm{T} 2$ male patient subgroup. Another study found an inverse correlation between proliferation activity and worse OS, ${ }^{10}$ which is inconsistent with our results; however, decreased proliferation activity in diffuse-type or signet-ring cell carcinomas was also reported in that study, ${ }^{10}$ which is consistent with our data. Although our results could not resolve all ambiguities surrounding the question of the prognostic significance of proliferation activity in gastric cancer, the results did demonstrate definitive significance for a specific subgroup.

To date, it is unclear how the subgroup specificity of the prognostic significance of proliferation activity in gastric cancer can be explained. Such subgroup specificities have already been reported for other cancers, for example, breast cancer, ${ }^{19-23}$ but not in gastric cancer. In the present study, the cancer tissues of the male patients showed a significantly higher CPCC than those of the female patients, which could be related to biological or hormonal differences. Indeed, the protective roles of female hormones, in terms of gastric cancer, have already been delineated. ${ }^{24}$ In addition to the gender difference, our data suggested that invasion depth is an important confounding factor in terms of the prognostic significance of proliferation activity in gastric cancer. Because the CPCC was higher in advanced $\mathrm{T}$ cancers, and because the prognostic significance of the CPCC was shown only in T1 or T2 male patients but not in T3 or T4 male patients, the growth rate might be important to patient survival only in early $\mathrm{T}$ gastric cancer, whereas cancer 

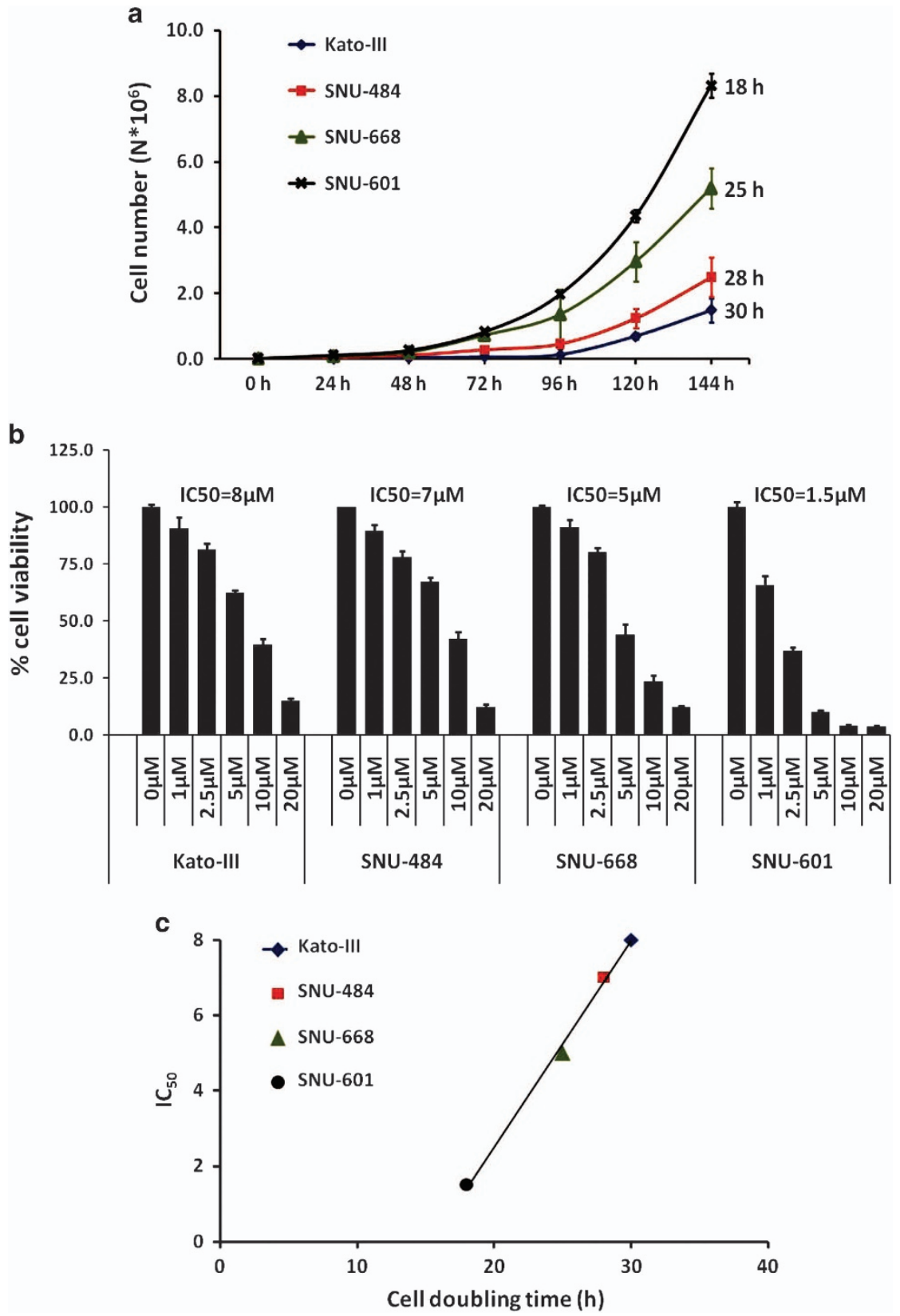

Figure 3 Correlation between cell doubling time and sensitivity to cisplatin in male gastric cancer cells. (a) Cell growth as measured by counting cell number (mean \pm s.e.m., $N=3$ ) at the indicated time points for the following male gastric cancer cell lines: Kato III, SNU-484, SNU 601, and SNU-668. The cell doubling time (calculated by the exponential regression method) for each cell is indicated at the end of the graph line. (b) Sensitivity to cisplatin, as measured by crystal violet after the treatment with various concentrations of cisplatin, is indicated on the $x$ axis for $72 \mathrm{~h}$. On the $y$ axis, the percentage of viable cells (mean \pm s.e.m., $N=5$ ) after calculating the ratios between the treated and the control cells is shown. The $I_{50}$ is shown for each cell line. (c) Positive correlation between shorter cell doubling time and higher sensitivity to cisplatin $(R=0.999, P=0.083)$. On the $x$ axis is the cell doubling time; on the $y$ axis, the $I_{50}$.

cell invasion and escape from anatomical barriers might be more important in cases of advanced $\mathrm{T}$ disease. Accordingly, the present study's analysis of relevant factors, such as gender and $\mathrm{T}$ classification, led to the identification of a specific gastric cancer subgroup for which the CPCC or proliferation activity has prognostic significance. In fact, successful targeted therapy for HER2-amplified gastric cancer patients strongly suggests the existence of therapeutically meaningful gastric cancer subgroups, ${ }^{25}$ even if the molecular classification of that malignancy is still in its infancy. Significantly, a recent molecular analysis indicated that $37 \%$ of gastric cancer cases can be classified based on the copy gains of five drug-target genes, ${ }^{26}$ which again strongly suggests the existence of gastric cancer subgroups.

The identification of the $\mathrm{T} 1$ or $\mathrm{T} 2$ male subgroup in gastric cancer, as based on the CPCC or proliferation activity, might 
have clinical implications for chemotherapeutic intervention, given that highly proliferating cells are generally more susceptible to chemotherapy. ${ }^{27}$ The importance of proliferation activity in the setting of breast cancer chemotherapy intervention has already been indicated, specifically for stronger responses to chemotherapy in cases of higher proliferation indices. $^{28,29}$ In the present study, we showed a positive correlation between shorter DT and higher sensitivity to cisplatin in male gastric cancer cell lines. If highly proliferative gastric cancer cells are more susceptible to chemotherapy, T1 or T2 male gastric cancer patients with highly proliferative cancer cells might be better candidates for chemotherapy. Further chemotherapeutic intervention studies of this subgroup could reveal additional clinical implications.

Although we did not validate the prognostic significance of the CPCC in T1 and T2 male patients in an independent set of gastric cancer cases, we did estimate the prognostic significance among the largest gastric cancer cohort (437) studied thus far (the relevant previous studies have all studied approximately 200 cases $\left.^{6,7,9,10}\right)$.

In conclusion, we identified the prognostic significance of the CPCC in a subgroup of T1 or T2 male gastric cancer patients, thus making a constructive contribution to the greater prognosis-based classification of gastric cancer. Furthermore, our results suggest that a T1 or T2 male gastric cancer patient subgroup with high proliferation activity is an excellent candidate for adjuvant chemotherapy, the data from which will facilitate additional clinical chemotherapeutic trials with this gastric cancer subgroup.

\section{CONFLICT OF INTEREST}

The authors declare no conflict of interest.

\section{ACKNOWLEDGEMENTS}

This work was supported by research grants to K-MH from the National Cancer Center, Korea (1510121 and 1410674) and by a grant to JR from the National Research Foundation, Korea

(NRF-2012R1A1A2001871).

Author contributions: Y-WK and K-MH conceived and designed the experiments. B-WE, M-CK, H-SK, H-LH, VC, SP, YS and J-SK performed the experiments. Y-WK, B-WE, M-KK and JR analyzed the data. Y-WK, M-CK and C-DB contributed reagents/materials/analysis tools. Y-WK, JR and K-MH wrote the paper.

1 van Diest PJ, Brugal G, Baak JP. Proliferation markers in tumours: interpretation and clinical value. J Clin Pathol 1998; 51: 716-724.

2 van Diest PJ, van der Wall E, Baak JP. Prognostic value of proliferation in invasive breast cancer: a review. J Clin Pathol 2004; 57: 675-681.

3 Prayson RA. Malignant meningioma: a clinicopathologic study of 23 patients including MIB1 and p53 immunohistochemistry. Am J Clin Pathol 1996; 105: 719-726.

4 Lee JR, Joshi V, Griffin JW Jr, Lasota J, Miettinen M. Gastrointestinal autonomic nerve tumor: immunohistochemical and molecular identity with gastrointestinal stromal tumor. Am J Surg Pathol 2001; 25: 979-987.

5 Pich A, Chiusa L, Navone R. Prognostic relevance of cell proliferation in head and neck tumors. Ann Oncol 2004; 15: 1319-1329.

6 Tsamandas AC, Kardamakis D, Tsiamalos P, Liava A, Tzelepi V, Vassiliou V et al. The potential role of $\mathrm{Bcl}-2$ expression, apoptosis and cell proliferation
(Ki-67 expression) in cases of gastric carcinoma and correlation with classic prognostic factors and patient outcome. Anticancer Res 2009; 29: 703-709.

7 Lazar D, Taban S, Sporea I, Dema A, Cornianu M, Lazar E et al. Ki-67 expression in gastric cancer. Results from a prospective study with long-term follow-up. Rom J Morphol Embryol 2010; 51: 655-661.

8 Xiao LJ, Zhao S, Zhao EH, Zheng X, Gou WF, Takano Y et al. Clinicopathological and prognostic significance of $\mathrm{Ki}-67$, caspase-3 and p53 expression in gastric carcinomas. Oncol Lett 2013; 6: 1277-1284.

9 Joo YE, Chung IJ, Park YK, Koh YS, Lee JH, Park CH et al. Expression of cyclooxygenase-2, p53 and $\mathrm{Ki}-67$ in gastric cancer. J Korean Med Sci 2006; 21: 871-876.

10 Lee HE, Kim MA, Lee BL, Kim WH. Low Ki-67 proliferation index is an indicator of poor prognosis in gastric cancer. J Surg Oncol 2010; 102: 201-206.

11 Fujii R, Seshimo A, Kameoka S. Relationships between the expression of thymidylate synthase, dihydropyrimidine dehydrogenase, and orotate phosphoribosyltransferase and cell proliferative activity and 5-fluorouracil sensitivity in colorectal carcinoma. Int J Clin Oncol 2003; 8: 72-78.

12 Penault-Llorca F, Andre F, Sagan C, Lacroix-Triki M, Denoux Y, Verriele V et al. Ki67 expression and docetaxel efficacy in patients with estrogen receptor-positive breast cancer. J Clin Oncol 2009; 27: 2809-2815.

13 Hugh J, Hanson J, Cheang MC, Nielsen TO, Perou CM, Dumontet C et al. Breast cancer subtypes and response to docetaxel in node-positive breast cancer: use of an immunohistochemical definition in the BCIRG 001 trial. J Clin Oncol 2009; 27: 1168-1176.

14 Carey LA, Dees EC, Sawyer L, Gatti L, Moore DT, Collichio F et al. The triple negative paradox: primary tumor chemosensitivity of breast cancer subtypes. Clin Cancer Res 2007; 13: 2329-2334.

15 Liedtke C, Mazouni C, Hess KR, Andre F, Tordai A, Mejia JA et al. Response to neoadjuvant therapy and long-term survival in patients with triple-negative breast cancer. J Clin Oncol 2008; 26: 1275-1281.

16 Nishimura R, Osako T, Okumura Y, Hayashi M, Arima N. Clinical significance of $\mathrm{Ki}-67$ in neoadjuvant chemotherapy for primary breast cancer as a predictor for chemosensitivity and for prognosis. Breast Cancer 2010; 17: 269-275.

17 Hong KU, Choi YB, Lee JH, Kim HJ, Kwon HR, Seong YS et al. Transient phosphorylation of tumor associated microtubule associated protein (TMAP)/cytoskeleton associated protein 2 (CKAP2) at Thr-596 during early phases of mitosis. Exp Mol Med 2008; 40: 377-386.

18 Kim HS, Choi YB, Lee JH, Park SY, Kim HK, Koh JS et al. Condensed chromatin staining of CKAP2 as surrogate marker for mitotic figures. J Cancer Res Clin Oncol 2012; 138: 95-102.

19 Kim HS, Koh JS, Choi YB, Ro J, Kim HK, Kim MK et al. Chromatin CKAP2, a new proliferation marker, as independent prognostic indicator in breast cancer. PLOS ONE 2014; 9: e98160.

20 Klintman M, Strand C, Ahlin C, Beglerbegovic S, Fjallskog ML, Grabau D et al. The prognostic value of mitotic activity index (MAI), phosphohistone H3 (PPH3), cyclin B1, cyclin A, and Ki67, alone and in combinations, in node-negative premenopausal breast cancer. PLoS ONE 2013; 8: e81902.

21 Nishimura R, Osako T, Okumura Y, Hayashi M, Toyozumi Y, Arima N. Ki-67 as a prognostic marker according to breast cancer subtype and a predictor of recurrence time in primary breast cancer. Exp Ther Med 2010; 1: 747-754.

22 Aleskandarany MA, Green AR, Benhasouna AA, Barros FF, Neal K, Reis-Filho JS et al. Prognostic value of proliferation assay in the luminal, HER2-positive, and triple-negative biologic classes of breast cancer. Breast Cancer Res 2012; 14: R3.

23 Munzone E, Botteri E, Sciandivasci A, Curigliano G, Nole F, Mastropasqua $\mathrm{M}$ et al. Prognostic value of $\mathrm{Ki}-67$ labeling index in patients with nodenegative, triple-negative breast cancer. Breast Cancer Res Treat 2012; 134: 277-282

24 Freedman ND, Lacey JV Jr, Hollenbeck AR, Leitzmann MF, Schatzkin A, Abnet CC. The association of menstrual and reproductive factors with upper gastrointestinal tract cancers in the NIH-AARP cohort. Cancer 2010; 116: $1572-1581$.

25 Bang YJ, Kim YW, Yang HK, Chung HC, Park YK, Lee KH et al. Adjuvant capecitabine and oxaliplatin for gastric cancer after D2 gastrectomy (CLASSIC): a phase 3 open-label, randomised controlled trial. Lancet 2012; 379: 315-321.

26 Deng N, Goh LK, Wang H, Das K, Tao J, Tan IB et al. A comprehensive survey of genomic alterations in gastric cancer reveals systematic patterns of molecular exclusivity and co-occurrence among distinct therapeutic targets. Gut 2012; 61: 673-684. 
27 Chabner BA. Antineoplastic Agents: Goodman \& Gilman's The Pharmacological Basis of Therapeutics. McGraw-Hill: New York, NY, USA, 2011.

28 Amadori D, Nanni O, Marangolo M, Pacini P, Ravaioli A, Rossi A et al. Disease-free survival advantage of adjuvant cyclophosphamide, methotrexate, and fluorouracil in patients with node-negative, rapidly proliferating breast cancer: a randomized multicenter study. J Clin Oncol 2000; 18: 3125-3134.

29 Keam B, Im SA, Lee KH, Han SW, Oh DY, Kim JH et al. Ki-67 can be used for further classification of triple negative breast cancer into two subtypes with different response and prognosis. Breast Cancer Res 2011; 13 . R22 (c) (i)

This work is licensed under a Creative Commons Attribution 4.0 International License. The images or other third party material in this article are included in the article's Creative Commons license, unless indicated otherwise in the credit line; if the material is not included under the Creative Commons license, users will need to obtain permission from the license holder to reproduce the material. To view a copy of this license, visit http:// creativecommons.org/licenses/by/4.0/

Supplementary Information accompanies the paper on Experimental \& Molecular Medicine website (http://www.nature.com/emm) 